\title{
A educação sexual e o papel do educador: reflexões a partir de um contexto social em transformação
}

\author{
Sexual education and the role of educator: Reflections from a \\ transformative social context
}

\section{Educación sexual y el papel del educador: Reflexiones de un contexto social transformador}

Aline Patrícia Souza Graduada em Pedagogia e Psicologia, Especialista em Neuropsicologia pelo Instituto de Psicologia, Educação e Saúde de São José do Rio Preto

Pós-graduada em Gestão Escolar no Centro Universitário Barão de Mauá Mestranda em Educação Sexual na Universidade Estadual Paulista “Júlio de Mesquita Filho”, em Araraquara. aps.alinepatricia@gmail.com

Débora Raquel da Costa Milani Graduada em Pedagogia, Especialização em Educação à Distância pelo UNISEB, Especialização em (PLA) Práticas de Letramento e Alfabetização e Especialização em Educação Empreendedora, Especialização em Psicopedagogia Institucional, Mestrado em Educação Escolar pela Universidade Estadual Paulista Júlio de Mesquita Filho e Doutorado em Educação Escolar, pela Universidade Estadual Paulista Júlio de Mesquita Filho. deb.milani@yahoo.com.br

Paulo Rennes Marçal Ribeiro Graduado em Pedagogia e Psicologia, Doutor em Saúde Mental pela Faculdade de Ciências Médicas da UNICAMP e Livre-Docente em Sexologia e Educação Sexual pela Universidade Estadual Paulista "Júlio de Mesquita Filho", em Araraquara, onde é Professor Associado do Departamento de Psicologia da Educação e do Mestrado em Educação Sexual.

paulorennes@fclar.unesp.br

Resumo: Partimos do princípio que Educação Sexual é um dos mais polêmicos assuntos, tendo em vista os diversos olhares, percepções e concepções existentes, recheados de diferentes valores presentes na sociedade. Dentre os estudiosos que se aventuram em investir na compreensão da sexualidade estão alguns profissionais da saúde e da educação, para quem direcionamos este artigo, que tem como objetivo refletir sobre os conceitos de Educação, Educador e Educação Sexual, levando o leitor a ponderar suas convicções sobre o papel de educador e refletir sobre a necessidade da ampliação desta temática para áreas de atuação além da Educação e Saúde. Trabalhar com Educação Sexual é uma possibilidade que vai além do ambiente escolar e médico, principalmente no momento atual em que as relações sociais se expandem em diferentes espaços e áreas profissionais começam a surgir para dar conta da demanda de questões ligadas à sexualidade. As reflexões aqui descritas, são decorrentes de leituras bibliográficas, que levam à conclusão que, mesmo diante de inúmeros desafios da Educação Sexual, todo cidadão pode ser educador em sexualidade, desde que exista nele o interesse pelos estudos e pesquisas para aprofundamento sobre a temática, encarando-a como formativa e de cunho científico.

Palavras-chave: Educação. Educação Sexual. Sexualidade. 


\title{
Dialogia
}

SOUZA, Aline Patrícia; MILANI, Debora Raquel da Costa; RIBEIRO, Paulo Rennes Marçal. A Educação sexual e o papel do educador: reflexões a partir de um contexto social em transformação

\begin{abstract}
Sex education is one of the most controversial subjects due to the various thoughts and ideas composed of different values present in society. Among the researchers who venture to invest in understanding sexuality are health professionals and teachers, to whom we direct this article, which aims to reflect on the concept of Education, Educator and Sex Education, leading the reader to ponder their convictions about the role of educator and reflect on the need to expand this theme to areas of activity beyond education and health. Working with Sex Education is a possibility that goes further than just the school and medical environment, especially in the present day where social relationships are expand to different means and professional areas are beginning to emerge to meet the demand for issues related to sexuality. Finally, based on bibliographic research, the reflections described here lead to the conclusion that even in the face of numerous challenges of Sex Education, every person can be an educator in sexuality, as long as there is an interest in they dedicate themselves in learning the subject, considering it as formative and scientific in nature.
\end{abstract}

Keywords: Education. Sex education. Sexuality.

Resumen: La educación sexual es uno de los temas más controversiales, teniendo en cuanta los diversos puntos de vista llenos de diferentes opiniones presentes en la sociedad. Entre los académicos que se aventuran a invertir en la comprensión de la sexualidad se encuentran algunos profesionales de la salud y otros en educación. Esta investigación tiene como objetivo reflexionar sobre el concepto de educación, educador y educación sexual, llevando al lector a meditar sobre sus convicciones en su rol y analizar sobre la necesidad de expandir este tema a áreas más allá de la educación y la salud. Se puede ver entonces, que trabajar con Educación Sexual es una posibilidad, especialmente en la actualidad, donde las relaciones sociales se expanden por diferentes medios, vemos otros espacios y áreas profesionales que comienzan a surgir para dar cuenta de la demanda de problemas con relación a la sexualidad. Las ideas descritas aquí, basado en la investigación bibliográfica, conducen a la conclusión que, frente a innumerables desafíos de la educación sexual, cada ciudadano puede ser un educador sexual, siempre que haya interés y un bagaje de estudios e investigaciones para profundizar en el tema, considerándolo como formativo e impreso científico.

Palabras llave: Educación. Educación sexual. Sexualidad.

\section{Introdução}

Nos últimos anos temos verificado em diversos contextos, debates acalorados entre defensores e opositores da Educação Sexual, assim como esforços de pesquisadores e estudiosos para aclarar o assunto e mostrar sua importância, especialmente para a vida plena de crianças e adolescentes. Um desses esforços é a desconstrução da visão unicamente biológica que se dá à sexualidade quando se pensa em um trabalho educativo.

Em grande parte dos trabalhos científicos publicados, vê-se que aqueles que mais debatem a sexualidade são profissionais atuantes na saúde e na educação, dando margem a interpretações errôneas dentre as quais a Educação Sexual seria atividade atribuída a enfermeiros e professores. Este automatismo pode ser justificado pelo fato de que os postos de saúde e escolas são locais com recursos físicos e profissionais mais favoráveis para orientar sobre sexualidade, o primeiro por estar diretamente ligado aos cuidados da saúde, já a segunda por representar um espaço significativo 
para promovê-la, uma vez que depois do ambiente familiar, a escola é o local onde crianças e adolescentes passam grande parte de seus dias. (HOLANDA, ALBUQUERQUE, MACHADO e VIEIRA, 2010).

De forma descritiva, esta pesquisa compreende os conceitos de Educação, de Educador e de Educação Sexual, de forma que repensemos nas incumbências do educador e além disso, reflitamos sobre a necessidade de emersão destes temas em áreas de atuação além da educação e da saúde. A coleta destes dados se deu por meio da leitura de publicações de autores que são referências nos estudos envolvendo sexualidade, as quais contribuíram para as interpretações e conclusões aqui citadas.

Ao falarmos sobre educação, a sociedade insiste em afirmar que esta acontece só no ambiente escolar, porém, como bem descrito por Brandão (1982, p.7) "[...] de um modo ou de muitos todos nós envolvemos pedaços da vida com ela: para aprender, para ensinar, para aprender e ensinar. Para saber, para faz̧er, para ser ou para conviver, todos os dias misturamos a vida com a educação". Todavia, a educação acontece em todas as instâncias onde ocorrem as relações sociais e segundo Silva (2012), ela aparece em nossas ações, em nossos valores e em como lidamos com o outro.

A educação acontece em todos os lugares, em todas as comunidades, com todos os indivíduos. Educar é compartilhar conhecimentos, é conduzir as pessoas a se tornarem cientes de fatos, adotando postura crítica a ponto de mudar sua própria visão de mundo. Não existe uma fórmula para que a educação aconteça. Educar envolve o aprender e, para isso, basta existir um sujeito que se relacione com seu meio. Por esta razão, educação não é sinônimo de ensino escolar.

Educação é uma ação natural provinda do compartilhar com o outro, ela não existe sem razão, ao contrário, acontece sempre com uma finalidade dentro de cada comunidade, sendo utilizada como instrumento para manter hábitos sociais, ou ainda, para gerar transformações. (LUCKESI, 2001).

À vista disso, cada um de nós contribui com a construção dinâmica dos sujeitos, a qual engloba aspectos sensoriais, intelectuais e emocionais destes sujeitos, permitindo a eles condições de organizar referencias de juízo de valores e atitudes que, juntos, constroem a integração pessoal. Isso é, também, educação. (MORAN, MASETTO e BEHRENS, 2009).

A educação, diferente da escolarização, é um fenômeno que se molda de acordo com a conformidade em que acontece e está presente nas condições sociais onde existe o ensinar e o aprender, "[...] é, como outras, uma fração do modo de vida dos grupos sociais que a criam e recriam, entre tantas outras invenções de sua cultura, em sua sociedade.” (BRANDÃO, 1982, p. 10). 


\section{Dialogia}

SOUZA, Aline Patrícia; MILANI, Debora Raquel da Costa; RIBEIRO, Paulo Rennes Marçal. A Educação sexual e o papel do educador: reflexões a partir de um contexto social em transformação

Ao escrever sobre registros de antropólogos em seus estudos sobre tribos nativas de diversos países, Brandão (1982) reflete sobre a sabedoria cultural acumulada pelo grupo, passada sem a existência de aulas e sem a necessidade da escola, com o peculiar objetivo de formar indivíduos funcionais dentro daquela comunidade específica, porque no fim "Tudo o que se sabe aos poucos se adquire por viver muitas e diferentes situações de trocas entre pessoas, com o corpo, com a consciência, com o corpo-e-a-consciência." (BRANDÃO, 1982, p. 18).

De acordo com o mesmo autor, a educação pode existir fora da escola, uma vez que o envolvimento social permite a transferência do saber de uma geração para outra, sem se preocupar com um modelo de ensino,

porque a educação aprende com o homem a continuar o trabalho da vida. A vida que transporta de uma espécie para a outra, dentro da história da natureza, e de uma geração a outra de viventes, dentro da história da espécie, os princípios através dos quais a própria vida aprende e ensina a sobreviver e a evoluir em cada tipo de ser. (BRANDÃO, 1982, p. 13).

Ao abordar sexualidade, a compreensão sobre educação neste contexto não deveria ser diferente, visto que a sexualidade é parte integral da vida de todo o ser humano, constituída em meio as estruturas sociais. (WAS - WORLD ASSOCIATION FOR SEXOLOGY, 1997).

Contudo, falar sobre sexualidade, embora seja necessidade constante, ainda envolve certa fragilidade por parte de alguns indivíduos, principalmente quando, aparentemente, não há motivos urgentes para se investir em Educação Sexual. Neste viés, Leão e Scalia (2009) apontam que a sociedade apenas se deu conta da precisão de ações educativas em sexualidade ao presenciar maior incidência de gravidez na adolescência e aumento das Infecções Sexualmente Transmissíveis (IST), sendo estas umas das principais causas motivadoras para buscar soluções de caráter educativo. Estas razões reforçam a ideia equivocada de que Educação Sexual é de competência exclusivamente das áreas da saúde e, por chamar-se educação, da instituição escolar.

Nas palavras de Figueiró (2001), a sexualidade não pode permanecer restrita a uma abordagem biologizante, pois é uma dimensão essencial humana, cujas significações e vivências são determinadas pela natureza e subjetividade de cada ser humano e, sobretudo, pela cultura, que deve ser compreendida, em sua totalidade e globalidade, como uma construção social que é condicionada pelos diferentes momentos históricos, econômicos, políticos e sociais.

Não obstante, um dos contribuintes para os retrocessos presentes na Educação Sexual é o fato de que a sociedade atual tende a reprimir assuntos relacionados à sexualidade, enquadrando-a 
em estruturas sociais, ofuscando sua representação e identidade, avigorando tabus e deixando de refletir sobre os inúmeros significados que envolvem o tema. (FIGUEIRÓ, 2004).

Este retrocesso é compreendido como parte do caminho histórico social que envolve a Educação Sexual em nosso país (RIBEIRO, 2017), caminho este iniciado já nas primeiras décadas do século XX, quando surgiram os primeiros estudos sobre educação sexual no Brasil (REIS e RIBEIRO, 2004). Desde então, lutamos pela construção de uma educação livre de preconceitos, discriminações e violências, prezando pelo respeito à diversidade e ao conhecimento, ainda que nos dias atuais nos deparemos com desafios nascidos de nossa própria época.

O conhecimento histórico é de grande importância como coadjutor da consolidação da Educação Sexual enquanto campo de ciência e prática educacional. Atitudes e comportamentos sexuais, assim como valores, variam de época para época e de povo para povo. São decorrentes de uma construção histórica. (RIBEIRO, 2017, p. 12).

Indo além dos muros escolares, a sociedade como um todo, e em particular as famílias, precisam compreender o significado e a abrangência da Educação Sexual:

Para que a sociedade compreenda a importância da Educação Sexual, é essencial que sua concepção advenha da construção histórica de seu significado, primeiramente nos ambientes mental e social, e em seguida no ambiente escolar, pois a Educação Sexual é resultante de um processo de preparação da sociedade para sua compreensão, valoração e aceitação. A percepção e concepção da Educação Sexual são influenciadas pela cultura sexual brasileira: os valores, os tabus, os preconceitos, os comportamentos, as atitudes e o que pensamos constituem os elementos que compõem a nossa cultura sexual. É a cultura sexual brasileira que prepara os ambientes mental, social e escolar para a aceitação da Educação Sexual, desde a Colônia até nossos dias. (RIBEIRO, 2019, p. 29).

Por conseguinte, para avançarmos nos quesitos que abrangem a sexualidade na educação, é necessário olhar a Educação Sexual como qualquer outra fonte de educação que distingue representações e valores para cada indivíduo. Neste aspecto, Silva (2012) desperta os educadores para desenvolver situações onde estejam envolvidos conteúdos filosóficos, éticos e políticos que contribuam para o reconhecimento de direitos e identidades ligados à sexualidade.

Ribeiro (2017) salienta que investir em Educação Sexual enquanto campo de saber científico possibilita a aquisição de maior compreensão de questões que envolvam a sexualidade, desconstruindo preconceitos e valores decorrentes do senso comum que se encontram incrustrados na cultura e na sociedade. 


\section{Dialogia}

SOUZA, Aline Patrícia; MILANI, Debora Raquel da Costa; RIBEIRO, Paulo Rennes Marçal. A Educação sexual e o papel do educador: reflexões a partir de um contexto social em transformação

Assim posto, para que a Educação Sexual ocorra de forma abrangente e construtiva, é preciso olhar para a formação do educador que deverá ter a importante tarefa de desconstruir e transformar valores e visão de mundo fundados em discriminação, tabus e preconceitos misóginos, homofóbicos e autoritários que direcionaram de forma equivocada a percepção da sexualidade e seus contornos.

Todavia, ser educador não é sinônimo de ser professor. Ser professor é ter uma profissão dentro da área da Educação. Brandão (1982) após concluir que a educação pode existir livre de sistemas, acontecendo em todas as instâncias - casa, na rua ou na igreja - justifica que não há como esquivarmos do educar, afinal, dependemos disto para tornar as coisas comuns, para criar e recriar nossa cultura e, sobretudo, para aprender a viver, concluindo assim, que todos nós somos e podemos ser educadores.

Silva (2012) corrobora com a ideia de que somos todos educadores, defendendo que desde os pais até a comunidade em geral contribuímos para a construção de ideais que gerarão valores e sentimentos diante de determinado tema. Esta tarefa de "transmitir algo" é por si só, educativa. Para ser educador, não basta ser profissional da educação, não basta apenas utilizar-se de informações técnicas sobre o ensinar, é preciso antes de tudo, olhar para si mesmo e entender suas próprias visões, agregando as visões daqueles que nos rodeiam:

Nenhuma organização é capaz de, sozinha, realizar ações que assegurem saúde e desenvolvimento pleno dos adolescentes. A família representa um dos eixos no desenvolvimento da orientação sexual de adolescentes, portanto, acredita-se que o sucesso da orientação sexual depende das alianças e parcerias intersetoriais que possam valorizar as potencialidades e reduzir as limitações [...]. (HOLANDA, FROTA, MACHADO, VIEIRA; 2010, p. 707).

Ser educador é contribuir para o amadurecimento intelectual e emocional que facilitará o processo de aprendizagem. Para tanto, faz-se necessário preparo e formação para que cada indivíduo crie sua própria prática de educação através de suas reflexões baseadas em sua vivência. Estas reflexões devem ser críticas e transformadoras para tornar-se educador. Como relata Paulo Freire (1991) apud Freitas e Forster (2016, p. 58): "Ninguém começa a ser educador numa certa terça-feira às quatro horas da tarde. Ninguém nasce educador [...] A gente se faz educador, na prática e na reflexão sobre a prática".

Logo, se todos nós podemos ser educadores, por que ser educador em Educação Sexual envolve desafios maiores? 
Para Nunes (2005) apud Silva (2012), abordar questões sobre sexualidade torna-se desafiador devido ao "estranhamento do sujeito bumano com sua própria sexualidade", uma vez que este sujeito, no caso o educador, vê-se envolto por valores morais e costumes sociais. Tais valores moldam seu comportamento e influenciam sua prática:

Nesta luta, para que ocorra a libertação dos homens e a verdadeira humanização não podemos depositar conteúdos nos homens, mas reconstruir a práxis juntos a ação e reflexão dos homens sobre o mundo para transformá-lo e problematizá-lo. Neste sentido, educador e educandos se tornam sujeitos do processo, se educam em comunhão e em participação. (PELLEGRIN, 2005, p. 6).

Assim, o educador sexual também é um agente de mudanças que estará em contato direto com o ambiente revelador, e sua ação é comprometedora, desafiante e exige autonomia.

\section{O Professor como educador sexual}

Frente ao exposto, após compreendermos o que é ser educador, voltamos à figura do professor, uma vez que este participa ativamente da formação de sujeitos, passando grande parte do tempo com crianças e adolescentes, formando vínculos de proximidade que permitem uma relação de confiança em ambas as partes. A este cabe a reflexão de seu próprio papel enquanto educador, como sujeito que sabe se organizar dentro de sua categoria política e profissional, como trabalhador na educação. (BRANDÃO, 1982).

Assim, o professor precisa se preparar para lidar com as temáticas que envolvem sexualidade, uma vez que é comum que assuntos a ela pertinentes venham à tona na sala de aula e fora dela (LEÃO e SCÁLIA, 2009). É frequente a expressão de sexualidade nas escolas advinda dos alunos em conversas, brincadeiras ou ainda em curiosas perguntas realizadas. Nestes momentos, espera-se que o professor saiba como tratar o assunto de forma a acolher e orientar o aluno. A sexualidade traz, entre seus inúmeros vínculos, o caráter social tornando imprescindível o envolvimento do professor, esperando que este adote postura de escuta aos alunos, cultivando o respeito e interação entre eles. (ARGENTI e MILANI, 2017).

De acordo com Figueiró (2006), o ofício do professor que se propõe a construir diálogos sobre a sexualidade no ambiente escolar visa 


\section{Dialogia}

SOUZA, Aline Patrícia; MILANI, Debora Raquel da Costa; RIBEIRO, Paulo Rennes Marçal. A Educação sexual e o papel do educador: reflexões a partir de um contexto social em transformação

criar oportunidades várias de reflexão, para que os alunos pensem e discutam com os colegas, a fim de que formem sua própria opinião sobre o sexo prématrimonial, masturbação, homossexualidade e aborto, entre outros. Cabe também ao professor fazer com que os alunos tenham acesso a informações claras, objetivas e científicas sobre sexualidade. (FIGUEIRÓ, 2006, p. 2).

Contudo, grande parte dos professores não se sente preparada para lidar com temas que envolvam a sexualidade. Tanferi (2013) justifica esta dificuldade como parte da construção social, onde para se trabalhar estes conceitos faz-se necessário, antes de tudo, desenvolver reflexões sobre si mesmo, se reconstruindo enquanto cidadão e também enquanto profissional. Por esta razão e por receios de serem reprimidos, alguns professores se sentem inibidos ao trabalhar Educação Sexual, pois além de compreender e intervir nas situações trazidas pelos alunos, ainda é necessário rever seus próprios conceitos e valores ligados à sexualidade.

Embora a proposta de refletir sobre si mesmo pareça de fácil execução, a prática traz desafios maiores que vão desde a carência de informações apropriadas durante a formação do professor e a falta de materiais que instrumentarão a prática profissional até a impossibilidade de acessar ou participar de espaços reflexivos para desconstruir preconceitos e desenvolver postura crítica e reformulação de atitudes frente ao sexo, revendo tabus para ser capaz de tratar com naturalidade as questões sexuais dos alunos.

Figueiró (1999), em suas práticas e convivência direta com professores, notou que eles vêm enfrentando diversas situações que envolvem manifestação da sexualidade, as quais necessitam de conhecimentos e habilidades específicas para serem trabalhadas na escola, incluindo apontamentos para o professor saber aproveitar as oportunidades que surgem no contexto escolar e até mesmo ensinar e orientar a partir delas. Ou seja, o professor necessita de uma formação específica em Educação Sexual que, além do conhecimento teórico e didático, também ofereça possibilidades para a compreensão do cotidiano escolar e dele extrair soluções criativas.

Outro conteúdo essencial para a formação em Educação Sexual é o político:

Consideramos que seja preciso reconhecer a Educação Sexual como um saber necessário que possibilite o rompimento de ideias repressoras, preconceituosas e discriminatórias cristalizadas ao longo da história, além de ser também uma ação de cidadania e direitos que estimule a formação de um ser humano consciente de como se processam as relações sociais. Toda ação educacional no espaço escolar deve ser formativa e humanizadora, daí a necessidade de pensá-lo como um local privilegiado para a formação de crianças e jovens. (MONTEIRO; RIBEIRO, 2020, p. 3) 
Justificadamente, cada vez mais pesquisas apontam para a necessidade de formação continuada para professores, assim como indicam a importância de incluir disciplinas sobre sexualidade e gênero nas grades dos cursos de licenciatura. A formação do professor que atuará em Educação Sexual deve estar fundamentada cientificamente na construção sócio-histórica do tema, sendo este o melhor caminho para a criação de uma educação emancipatória. (TANFERI, 2013). Para isso, espera-se que o professor mantenha-se em constante formação, aperfeiçoando sua prática e incentivando seus alunos a progredirem de forma autônoma, avaliando seus progressos e conscientizando-os de que a Educação Sexual também é um tipo de aprendizagem. (PELEGRIN, 2005).

Assim sendo, após investir em seu preparo pessoal e profissional para desenvolver atividades que abrangem a sexualidade, compete ao professor a função de facilitar e construir junto a seus alunos reflexões que garantirão aprendizagem significativa, tornando-os conscientes de seus atos, fazendo da Educação Sexual uma:

ferramenta fundamental para subsidiar discussões sobre as práticas e comportamentos dos jovens em relação aos riscos que envolvem a sexualidade, além de promover a prevenção de problemas futuros e proporcionar $\mathrm{O}$ conhecimento sobre o próprio corpo. (TANFERI, 2013, p. 13)

Continuando, Tanferi (2013) salienta que ao trabalhar sexualidade, o professor tem a nobre tarefa de desenvolver habilidades necessárias para o aproveitamento de conhecimentos específicos e saudáveis de tudo que se relaciona ao corpo e ao ser, despertando a construção de práticas positivas, seguras e responsáveis, incentivando os alunos a pensarem nestas questões além da sala de aula e/ou da escola, oferecendo espaço onde possam conversar, questionar e se expressar de forma crítica, reflexiva e construtiva.

Esta é a esperança que se pode ter na educação [...]. Acreditar que o ato humano de educar existe tanto no trabalho pedagógico que ensina na escola quanto no ato político que luta na rua por um outro tipo de escola, para um outro tipo de mundo. (BRANDÃO, 1982, p. 110).

Assim, a Educação Sexual reside particularmente na possibilidade de formar sujeitos mais preparados para a vida, que saibam se posicionar de forma crítica para existir com autonomia e integralidade. Para Figueiró (2001), a interpelação pedagógica deve ser o prolongamento saudável da sexualidade do indivíduo, que se sentirá mais feliz e transportará essa felicidade à esfera sexual, com benefícios à sua saúde e à vida na sociedade. 


\section{Dialogia}

SOUZA, Aline Patrícia; MILANI, Debora Raquel da Costa; RIBEIRO, Paulo Rennes Marçal. A Educação sexual e o papel do educador: reflexões a partir de um contexto social em transformação

\section{Considerações finais: educação sexual além da escola}

Embora inicialmente a ideia de trabalhar Educação Sexual tenha sido pensada para o contexto escolar, considerando as atuais relações sociais em que manifestações da sexualidade e suas concepções, valores e percepções ocorrem intensamente e surgem outras demandas que solicitam também ações de Educação Sexual, que se tornou uma área de atuação interdisciplinar e em múltiplos espaços. Vemos o crescimento do interesse e da participação de profissionais da Fisioterapia, Educação Física, Enfermagem, Psicologia, Pedagogia, Publicidade, Jornalismo, Recursos Humanos Empresariais, Medicina, Nutrição, Ciências Sociais, História, Letras dentre outras $^{1}$.

Estes vários profissionais podem oferecer à comunidade informações e orientações sobre sexualidade, não só em espaços reais como em espaços virtuais, intensificando o pensar a Educação Sexual enquanto ciência e ação pedagógica. Muitos espaços virtuais são considerados formadores de opinião, portanto, a informação ali divulgada precisa ser respaldada por estudos e pesquisas válidos, evitando as falsas divulgações, argumento pra defesa da Educação Sexual e da formação de educadores sexuais.

Tendo em vista as reflexões aqui descritas, concluímos que dentre os desafios da Educação Sexual encontra-se a propagação da percepção de que todo cidadão pode ser educador em sexualidade, desde que exista nele o interesse pelo saber sobre a temática, dispondo-se a refletir sobre sua própria sexualidade e a investir em uma formação voltada à Educação Sexual, possibilitando a si mesmo um processo de desconstrução e desmistificação de tabus e de formas de preconceito.

Por outro lado, conscientizar-se de que todos somos educadores sexuais tira o peso do professor e do enfermeiro de serem os únicos responsáveis pela Educação Sexual, assim como lembra a família e as demais instituições de se envolverem mais em práticas de educação, orientação e conscientização, fazendo com que a sociedade compreenda a abrangência da Educação Sexual.

\footnotetext{
${ }^{1}$ Estas áreas são as de formação dos alunos e alunas do Curso de Mestrado em Educação Sexual da Universidade Estadual Paulista "Júlio de Mesquita Filho”, em Araraquara SP, matriculados entre 2013 e 2019.
} 
SOUZA, Aline Patrícia; MILANI, Debora Raquel da Costa; RIBEIRO, Paulo Rennes Marçal. A Educação sexual e o papel do educador: reflexões a partir de um contexto social em transformação

\section{Referências}

ARGENTI, P. C.; MILANI, D. R. C. Educação Sexual e docência: As relações de gênero, a diversidade e a sexualidade dentro da escola. Doxa: Revista Brasileira de Psicologia e Educação - V. 19, nº 2, p. 212 223. Araraquara, 2017.

BRANDÃO, C. R. O que é educação. Editora Brasiliense. 5ª Revisão, São Paulo, 1982.

FIGUEIRÓ, M. N. D. A formação de educadores sexuais: possibilidades e limites. Tese (Doutorado em Educação). Universidade Estadual Paulista "Júlio de Mesquita Filho”. Marília, 2001.

FIGUEIRÓ, M. N. D. Educação Sexual: como ensinar no espaço da escola. Linhas. Florianópolis, v. 7, n. 1, 2006.

Disponível em: http://www.periodicos.udesc.br/index.php/linhas/article/view/1323. Acesso em 15 de fevereiro de 2017.

FIGUEIRÓ, M. N. D. Educação sexual no dia a dia. $1^{\text {a }}$ coletânea. Londrina: Moriá Gráfica e Editora Ltda, 1999.

FIGUEIRÓ, M. N. D. O professor como educador sexual: interligando formação e atuação profissional. In: RIBEIRO, P. R. M. (org.). Sexualidade e educação: aproximações necessárias. São Paulo: Arte e Ciência, 2004, p. 115-152.

FREITAS, A. L. S.; FOSTER, M. M. S. Paulo Freire na formação de educadores: contribuições para o desenvolvimento de práticas crítico-reflexivas. Educar em Revista. n. 61. Curitiba, 2016. p. 55-69.

HOLANDA, M. L.; ALBUQUERQUE, M.; MACHADO, M. F. A. S.; VIEIRA, V. F. C. O papel do professor na Educaşão Sexual de adolescentes. Revista Cogitare Enfermagem. V. 15, n. 4, Curitiba, 2010, p. 702-708.

LEÃO, A. M. C.; SCALIA, A. C.A M. A. Sexualidade na escola e o papel do educador: analisando a percepção de graduando em um curso de pedagogia. 2009. Disponível em https://repositorio.unesp.br/bitstream/handle/11449/139797/ISSN2175-7054-2009-92129223.pdf?sequence $=1$ Acesso em 15 de setembro de 2018 .

LUCKESI, C. C. Filosofia da educação. São Paulo: Cortez, 2001.

MONTEIRO, S. A. S.; RIBEIRO, P. R. M. Sexualidade e gênero na atual BNCC: possibilidades e limites. Revista Pesquisa e Ensino, UFOB, v. 1, 2020, p. 1-24.

MORAN, J. M.; MASETTTO, M.; BEHRENS, M. Novas tecnologias e mediação pedagógica. Campinas: Papirus, 2009, p.12-17.

PELLEGRIN, F. I. T. O educador: além de professor, filósofo da educação e líder da transformação social. Revista Eletrônica "Fórum Paulo Freire", Ano 1, n, 1, 2005, s/p. 
REIS, G. V.; RIBEIRO, P. R. M. A institucionalização do conhecimento sexual no Brasil. In: RIBEIRO, P. R. M. (Org.). Sexualidade e educação: aproximações necessárias. São Paulo: Arte \& Ciência Editora, 2004, p. 27-71.

RIBEIRO, P. R. M. Desafios contemporâneos em Educação Sexual: a perda do ambiente mental, social e escolar. In: DESIDÉRIO, R.; FIGUEIRÓ, M. N. D.; RIBEIRO, P. R. M.; MENDES, P.O. S. P.; MELO, S. M. M.; MAISTRO, V. I. A.; BASTOS, V. C. Interseccionalidade e transgressões em Educação Sexual. Londrina: Syntagma Editores, 2019, p. 29-39.

RIBEIRO, P. R. M. Educação para a sexualidade. Revista Diversidade e Educação, FURG, v. 5, n. 2, 2017, p. 07-15.

SILVA, R. D. Como tem sido as aulas de Educação Sexual nas escolas? Representações conceituais de professores na cidade de Londrina. Revista Travessias, v. 6, n. 2, 2012, p. 13-28.

TANFERI, J. A. O papel da educação na sexualidade do indivíduo: a educação sexual na escola. Universidade Estadual do Norte do Paraná (UENP), Campus de Jacarezinho, 2013. http://www.diaadiaeducacao.pr.gov.br/portals/cadernospde/pdebusca/producoes_pde/2013/2 013_uenp_cien_pdp_jorgina_aparecida_tanferi.pdf. Acesso em 20 de setembro de 2018.

WORLD ASSOCIATION FOR SEXOLOGY - WAS. Declaraşão dos direitos sexuais. Revista Terapia Sexual, São Paulo, v. 2, n. 2, 1999, p. 121-122.

Recebido em: 21 fev. 2020 / Aprovado em: 15 abr. 2020

\section{Cite como (ABNT NBR 6023:2018)}

SOUZA, Aline Patrícia; MILANI, Debora Raquel da Costa; RIBEIRO, Paulo Rennes Marçal. A Educação sexual e o papel do educador: reflexões a partir de um contexto social em transformação. Dialogia, São Paulo, n. 34, p. 95-106, jan./abr. 2020. Disponível em: https://doi.org/10.5585/Dialogia.N34.16635. 